\title{
INHALT \\ DES ZWEITEN TEILS
}

18. Buch (359): Julian unterwirft weitere Gaue der Alamannen Kriegsvorbereitungen des Perserkönigs Sapor - Antoninus, ein römischer Beamter, flieht zu den Persern - Sapor fällt in Mesopotamien ein - Beschreibung der Festung Amida - u. a. m.

19. Buch (359): Angriff der Perser auf Amida - Die Belagerung der Stadt und ihre Eroberung - Flucht des Ammianus Marcellinus aus der eroberten Stadt - Ein wohlhabender Bürger der Stadt Nisibis, Craugasius, geht zu den Persern über - Kämpfe mit den Sarmaten - Majestätsprozesse - u. a. m. . . . . . . . . . .

20. Buch (359-360): Kämpfe mit Scotten und Picten- Ursicinus wird aus dem Dienst entlassen - Julian wird in Paris zum Kaiser ausgerufen - Im Osten erobert Sapor die römischen Festungen Singara und Bezabde - Verhandlungen zwischen Julian und Constantius II. - Julian zieht gegen die attuarischen Franken zu Felde - u. a. m. . . . . . . . . . . . . . . . . .

21. Buch (360-361): Julian bezeitet sich zum Krieg gegen Constantius II, vor - Constantius II. heiratet Faustina - Er zieht Verstärkungen heran - Julian zieht durch das Donau-Tal, gewinnt Sirmium und besetzt den $\mathrm{Pa} B$ von Succi - Abfall und Belagerung von Aquileja - Tod des Constantius - u. a. m. . . . . . . . 126

Erläuterungen .................... . 174 